\title{
STUDIES ON THE EFFECT OF VARIATION OF CONCENTRATION AND ORIGIN OF LECITHIN (NATURAL AND SYNTHETIC) IN CARDIOLIPIN COMPLEMENT-FIXATION ANTIGEN*
}

\author{
BY \\ ALICE REYN AND MICHAEL WEIS BENTZON \\ From the Sero-diagnostic and Statistical Departments, Statens Seruminstitut, Copenhagen (Director: J. Ørskov, M.D.)
}

The significance of the relationship between the three components of cardiolipin complementfixation antigen, viz. cardiolipin, natural lecithin, and cholesterol, was first studied by Maltaner and Maltaner (1945) in experiments with syphilitic pooled rabbit or human sera. Suitable sensitivity with regard to the routine sero-diagnosis of syphilis was obtained with the antigen formula: Cardiolipin (C) 1, lecithin (L) 5, and cholesterol (Ch) 17.

A C/L ratio of $1 / 1 \cdot 5$ and a $C h / L$ ratio of 5 or $6 / 1$ appeared to form the upper limits of sensitivity. These results were confirmed by Lundbäck (1952). Other investigators (Harris and Portnoy, 1944; Kent, Boyd, and Sanders, 1948; Kolmer and Lynch, 1948) arrived at other suitable antigen formulae, and now at least six different formulae are in use (Chron. Wld Hlth Org., 1955).

Allen and Mason (1952) tested a larger series of human sera against four antigens with varying $\mathrm{C} / \mathrm{L}$ and $\mathrm{C} / \mathrm{Ch}$ ratios, and found the greatest sensitivity with antigen prepared with a $\mathrm{C} / \mathrm{L}$ ratio of $1 / 1 \cdot 7$ and a $\mathrm{C} / \mathrm{Ch}$ ratio of $1 / 10$; however, the high sensitivity was obtained at the price of lower specificity. Price (1953 a, b, c), using a Ch/L ratio of 10/1, considered a C/L ratio of $1 / 1$ to be most suitable for the Whitechapel complement-fixation technique. Later experiments showed that cardiolipin antigen of the above-mentioned composition "showed a greater liability to non-treponemal reactions" than the crude Price antigen formerly used (Price, 1954).

In a previous investigation (Reyn, Bentzon, and Hartmann, 1956), in which the same five freeze-dried syphilitic sera were repeatedly tested in complementfixation experiments, the individual sera were found to respond somewhat differently to variation of the lecithin concentration, keeping the $\mathrm{C}-$ and $\mathrm{Ch}-$ concentrations constant. The greatest sensitivity was

\footnotetext{
* Received for publication January 25, 1958.
}

obtained with a $C / L$ ratio of about $1 / 0.6$ and a $C h / L$ ratio of about 30/1. The experiments were carried out with a synthetic, saturated lecithin, crystalline L- $\alpha$-di-myristoyl phosphoryl choline (Baer, 1953).

The same series of experiments showed that the storage for 4 months at $56^{\circ} \mathrm{C}$. of antigens prepared with the crystalline synthetic lecithin in double the usual concentration resulted in a greater loss of sensitivity than the storage of antigens containing the usual lecithin concentration. This observation suggested that the lecithin was significant for the keeping qualities of cardiolipin antigen.

The purpose of the present investigations was to study the influence of variation in the concentration of the natural lecithins (egg and beef-heart) and to test whether the response to variation was uniform for syphilitic and biologically false-positive sera.

In addition, it was decided to test whether the observation on the correlation between the lecithin concentration and the keeping qualities could be applied to the natural lecithins.

Recently, Tonks, Allen, and Fowler (1955 a, b) reported that different amounts of various lecithins were needed to obtain "standard sensitivity", and Kline $(1950,1954,1955)$ found that the $C / L$ ratio in his test should be altered from about $1 / 10$ to about $10 / 9$ when crystalline synthetic L- $\alpha$-di-myristoyl lecithin was used instead of natural lecithin. $\dagger$ It was previously found (Reyn and others, 1956) that the average sensitivity obtained was the same as that of a reference antigen prepared with egg lecithin (International Reference Preparations, 1953) when the concentration (molecular weight basis) of the crystalline synthetic lecithin was reduced to about $\frac{1}{4}$ of that used for the egg lecithin in the reference antigen.

Previous observations (Reyn and others, 1956), as well as preliminary experiments in the present series,

t The preparations were compared on a unit/weight basis. 
suggested that the chemical nature of the lecithins was significant for the sensitivity, and perhaps also for the specificity, of the antigens. Theoretically, it was also possible that both specificity and the sensitivity might depend on the chemical structure of the fatty acids in the lecithins and that differences in the number of double bonds and in solubility might also be of significance. Hence, the effects of two synthetic lecithins, one unsaturated ( $\mathrm{L}-\alpha$-di-oleyl: Baer, Buchnea, and Newcombe, 1956) and one saturated (L- $\alpha$-di-myristoyl: Baer, 1953), were compared in complement-fixation experiments.

\section{Material}

Cardiolipin (International Reference Preparations for 1953) egg (E.) and beef-heart (B.) lecithins (IRP 1953). Cholesterol Pfanstiehl precipitated from ethanol. Samples of synthetic L- $\alpha$-di-oleyl (D.-O.) lecithin and L- $\alpha-$ di-myristoyl (D.-M.) lecithin were received from Professor Baer of Toronto at the request of the WHO Reference Centre, Statens Seruminstitut, Copenhagen. The preparations were received in September and October, 1955, and were kept at about $4^{\circ} \mathrm{C}$. until November 19, 1955, when ethanolic stock solutions containing $30 \mathrm{mg} . / \mathrm{ml}$. were prepared; the solutions were clear and colourless.

Antigens.-On September 2, 1955, six complementfixation (CF) antigens were prepared, using the IRP 1953 preparations of cardiolipin and lecithins; the lecithins were used $\frac{1}{2}$ "normal", "normal", and twice the "normal" concentration, the "normal" concentration being 0.0875 weight/volume per cent. The antigens were stored in sealed glass ampoules at room temperature when not otherwise indicated. Aliquots of each of the antigens were stored in sealed glass ampoules in a waterbath at $56^{\circ} \mathrm{C}$. for about 5 months.

On January 1, 1956, six CF antigens were prepared with cardiolipin (IRP 53) and either L- $\alpha$-di-oleyl (D.-O.) or L- $\alpha$-di-myristoyl (D.-M.) lecithin in $\frac{1}{4}$ "normal", and twice the "normal" concentration, the different molecular weights being taken into consideration. On April 17, 1956, eight CF antigens were prepared with the two synthetic lecithins in the following concentrations: $\frac{1}{16}, \frac{1}{8}, \frac{1}{4}$ "normal", and "normal". The molecular weights of the synthetic antigens were calculated at 803.7 for the D.-O. lecithin and at 695.6 for the D.-M. lecithin, whereas the molecular weights of the natural lecithins were calculated at 785, $P=3 \cdot 95$ per cent. (Pangborn, Maltaner, Tompkins, Beecher, Thompson, and Flynn, 1951).

The antigen containing $0.0875 \cdot$ weight/volume per cent. E. lecithin was used as a reference in most of the experiments.

Sera.-Freeze-dried, human, positive syphilitic and biologically false-positive (B.F.P.) sera, derived from various stages of syphilis and from cases with acute and chronic type of B.F.P. (Table, opposite).

Method.-Quantitative CF as modified by Mørch (1933). The method was recently described by Schmidt (1951) for use in experiments with cardiolipin antigen. Parallel serum dilutions (ten tubes) with a difference of 0.24 in logarithmic value between the tubes. The results were given as $\log _{10}$ titre values at 50 per cent. haemolysis, determined by the Kärber method (see e.g. Finney, 1947), Antigen/saline $1: 133$.

\section{Results and Discussion}

Experiments were undertaken in which the lecithin (L) concentration of cardiolipin antigen was varied, keeping the cardiolipin $(\mathrm{C})$ and cholesterol (Ch) concentrations constant. Thus the ratios between all three components were varied at one time. The antigens were all tested in the same final dilution in saline. It was not intended to analyse the significance of variation in the absolute and relative concentrations of the various components but only to follow up some of the indications found in a previous investigation. Repeated experiments were performed with two different sets of freeze-dried sera, comprising syphilitic and biologically-false positive (B.F.P.) sera. Details as to the experiments and to the statistical evaluation of the results will be furnished by the authors on request.

Synthetic Lecithins.-In the previous investigation (Reyn and others, 1956), using crystalline synthetic lecithin (L- $\alpha$-di-myristoyl phosphoryl choline $=$ D.-M.) in different amounts, the average sensitivity of a cardiolipin CF antigen with double the "normal" lecithin concentration was found to be considerably lower than that obtained with both "normal" and $\frac{1}{2}$ "normal" concentrations, the sensitivity of the latter being slightly higher than that of the former. In addition, the average sensitivity of the antigen prepared with the "normal" concentration of D.-M. lecithin was slightly lower than that found with the reference antigen containing egg (E.) lecithin in a "normal" concentration.

In the present series two sets of freeze-dried sera were repeatedly titrated against antigens prepared with $\mathrm{L}-\alpha$-di-oleyl (D.-O.) and L- $\alpha$-di-myristoyl (D.-M.) lecithins in different concentrations, keeping the cardiolipin and cholesterol concentrations constant. Each serum was tested on at least two experimental days, and the experiments were performed on January 13, 19, 21 and 23 and April 23 and 30, 1956.

In Figs 1 and 2 (overleaf) the average titre differences from the reference antigen (ordinate) are plotted against the lecithin concentration (abscissa) for each serum, separate plots being prepared for experiments in January and April. In addition, the titre differences between an incomplete antigen without lecithin (Card. Chol.; Schmidt, 1955 a, b) and the reference 
TABLE

INFORMATION ON SERA

\begin{tabular}{|c|c|c|c|c|c|c|c|}
\hline \multirow{2}{*}{$\begin{array}{l}\text { Freeze-dried } \\
\text { Serum No. }\end{array}$} & \multirow{2}{*}{ Clinical Information at Sampling } & \multirow{2}{*}{ Type of Serum } & \multirow{2}{*}{ Dates Tested } & \multicolumn{4}{|c|}{ Routine Results at Sampling } \\
\hline & & & & C-WR-M* & $\mathbf{K R}+\boldsymbol{t}$ & MR $\ddagger$ & $\mathrm{TPI}^{* *}$ \\
\hline 108 & $\begin{array}{l}\text { Primary and secondary syphilis: } \\
\text { Untreated? Re-infection } \quad .\end{array}$ & $\begin{array}{l}\text { Syphilitic } \\
\text { Acute in chronic }\end{array}$ & $\begin{array}{l}23.9 ; 27.9 ; 5.10 ; 14.10 \\
21.10 ; 11.111955\end{array}$ & $9^{*}$ & $6+$ & ++ & + \\
\hline 114 & Rezent secondary syphilis: Treated .. & $\begin{array}{l}\text { Syphilitic } \\
\text { Subacute }\end{array}$ & ", & 11 & 8 & ++ & + \\
\hline 120 & Tertiary syphilis in $1950:$ Treated & Syphilitic Chronic & , & 8 & 3 & ++ & + \\
\hline 105 & Primary syphilis: Treated & Syphilitic Acute & $\begin{array}{l}13.1 ; 20.1 ; 26.1 ; 7.2 \\
16.2 ; 23.4 ; 30.41956\end{array}$ & 8 & 5 & ++ & + \\
\hline 112 & Primary and secondary syphilis: Treated & Syphilitic Acute & $\begin{array}{l}13.1 ; 20.1 ; 23.4 ; 30.4 \\
1956\end{array}$ & 6 & 3 & \pm & + \\
\hline 124 & Primary syphilis: Re-infection & $\begin{array}{l}\text { Syphilitic } \\
\text { Acute in chronic }\end{array}$ & $13.1 ; 20.1 ; 26.1 ; 7.2$ & 14 & 10 & ++ & + \\
\hline 110 & Latent syphilis: Treated. . & $\begin{array}{l}\text { Syphilitic } \\
\text { Chronic }\end{array}$ & $\begin{array}{l}18.1 ; 23.1 ; 7.2 ; 16.2 ; \\
23.4 ; 30.41956\end{array}$ & 12 & 5 & ++ & + \\
\hline 123 & Syphilis in 1908: Treated & Syphilitic Chronic & , & 5 & 2 & + & + \\
\hline 125 & Tertiary syphilis in 1949: Gumma? . . & Syphilitic Chronic & , & 8 & 3 & + & + \\
\hline 130 & $\begin{array}{l}\text { Herpes genitalis? } \\
\text { Negative sero-reactions without } \\
\text { ment } \\
\end{array}$ & $\begin{array}{l}\text { Biologic False } \\
\text { Positive }\end{array}$ & $\begin{array}{l}23.9 ; 27.9 ; 5.10 ; 14.10 ; \\
21.10 ; 11.111955 \\
13.1 ; 20.1 ; 26.1 ; 9.2 \\
14.2 ; 23.4 ; 30.41956\end{array}$ & $?(7)$ & - & - & - \\
\hline 131 & $\begin{array}{c}\text { Primary atypical pneumonia } \\
\text { Negative sero-reactions without } \\
\text { ment } \\
\ldots\end{array}$ & $\begin{array}{l}\text { Biologic False } \\
\text { Positive Acute }\end{array}$ & " & $?(11)$ & - & - & - \\
\hline 132 & $\begin{array}{l}\text { Obs. pro ulcus ventriculi } \\
\text { Negative sero-reactions without treatment }\end{array}$ & $\begin{array}{l}\text { Biologic False } \\
\text { Positive Acute(?) }\end{array}$ & $\begin{array}{l}26.1 ; 9.2 ; 14.2 ; 23.4 ; \\
30.41956\end{array}$ & $?(6)$ & - & - & - \\
\hline 133 & $\begin{array}{l}\text { Arthrosis } \\
\text { On repeated testing constant positive } \\
\text { C-WR-M and KR } \ldots \\
\end{array}$ & $\begin{array}{l}\text { Biologic False } \\
\text { Positive Chronic }\end{array}$ & $\begin{array}{l}18.1 ; 23.1 ; 9.2 ; 14.2 \\
23.4 ; 30.41956\end{array}$ & 20 & 16 & - & - \\
\hline 134 & $\begin{array}{l}\text { Sailor: malaria in } 1941 . \\
\text { On repeated testing C-WR-M and KR } \\
\text { constant positive } \quad \ldots \\
\quad \ldots\end{array}$ & $\begin{array}{l}\text { Biologic False } \\
\text { Positive Chronic }\end{array}$ & $\begin{array}{l}23.9 ; 27.9 ; 5.10 ; 14.10 \\
21.10 ; 11.111955 \\
18.1 ; 23.1 ; 26.1 ; 9.2 \\
14.2 ; 23.4 ; 30.41956\end{array}$ & 11 & ?(9) & - & - \\
\hline
\end{tabular}

* Complement-fixation with cardiolipin antigen. Modification Morch (1933).

+ Degrees of strength.

$\ddagger$ Meinicke's clarification reaction.

antigen are plotted on the ordinate for each serum; the results with Card. Chol. were obtained from a protocol presented by Schmidt (1957).

The results for the two experimental periods (January and April, 1956) were plotted separately; only with Serum 124 does the deviation between the January and April results for antigens with "normal" lecithin concentration exceed the limits of error.

Figs 1 and 2 show that the individual sera responded somewhat differently to variations in lecithin concentration, the range of the deviation being greatest for the acute-type sera; this applied to both the D.-O. and the D.-M. lecithins.

The antigen with "normal" concentration of D.-M. lecithin showed an average sensitivity slightly lower than that of the reference antigen with $\mathrm{E}$. lecithin (average difference: $-0.04 \log _{10}$ values; range: $0.32 \log _{10}$ values); the antigen with twice the
** Qualitative Treponema Pallidum Immobilization Reaction. Nelson and Mayer (1949)

tt Kahn Standard with crude antigen

(?) Non-readable. Numbers in brackets estimated degrees of strength.

"normal" lecithin concentration was also far less sensitive than the reference antigen prepared with E. lecithin, the total average difference from the reference antigen being about $-0.52 \log _{10}$ values. Thus, in spite of the fact that two different sets of sera were tested, the response to variation in the lecithin concentration was about the same as in the previous series.

The antigens prepared with $\mathrm{L}-\alpha$-di-oleyl phosphoryl choline (D.-O.) and D.-M. lecithin behaved similarly towards variation in the concentration, the average sensitivity here being greater than that of the antigens containing D.-M. lecithin and the reference antigen; the latter was tested only at the "normal" concentration.

Theoretically, it was possible that the nature of the fatty acids in the lecithin might influence both the sensitivity and the specificity of the antigens. Some 


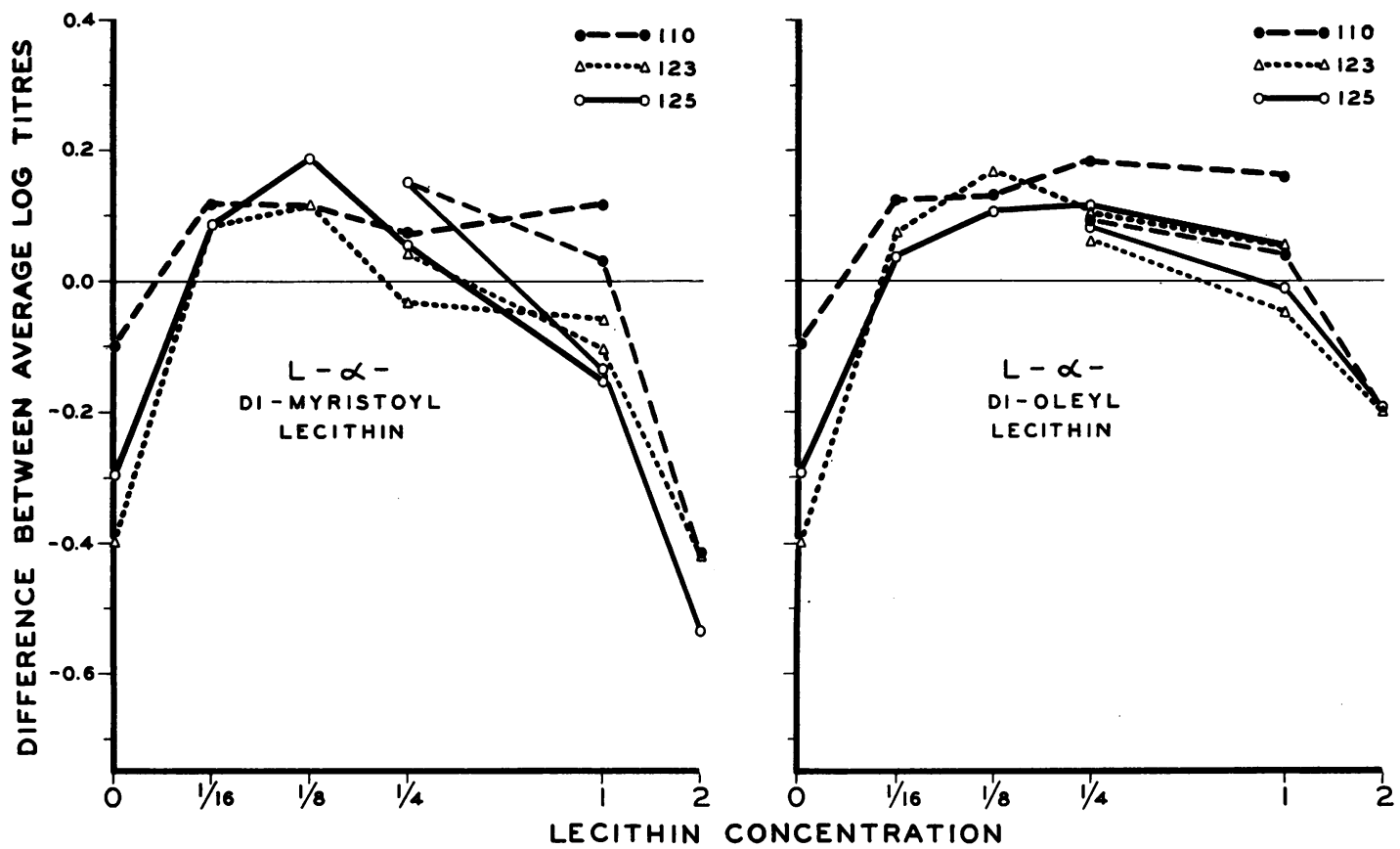

Fig.1.-Comparison between a reference antigen prepared with the "normal" (1) egg lecithin concentration and six test antigens with varied concentration of either L- $\alpha$-di-oleyl (D.-O.) lecithin or L- $\alpha$-di-myristoyl (D.-M.) lecithin.

Three acute type syphilitic sera.

Abscissa: Lecithin concentration; 0 corresponds to the results obtained with the incomplete Card. Chol. antigen.

Ordinate: Difference between the reference antigen and the various test antigens in $\log _{10}$ values.

such indication was found in the preliminary experiments. However, by displacement of the individual serum lecithin curves for the syphilitic sera, it was seen that on the average the same titres were obtained by using about 1.5 times less D.-M. than D.-O. lecithin; for the chronic-type sera this "relative potency" deviated but slightly from $1 \cdot 5$, whereas it varied from about 1 (Serum 124) to about 2 (Serum 112) for the acute-type sera. Thus, no major difference in the serum $\sim$ lecithin curves was demonstrated between the D.-M. and the D.-O. lecithins. If it is desired to obtain antigens with "standard sensitivity" it will be necessary to use different amounts of the two synthetic lecithins, perhaps about $\frac{1}{2}$ the "normal" concentrations of D. -M. and about 1.5 the "normal" concentration of D.-O. In this way one might obtain the same average sensitivity if a great number of sera were tested, though there would always be the risk that some special sera would respond differently (see results for the acute-type sera).

In previous studies on D.-M. lecithin, the range of deviation of the individual syphilitic sera was found to vary with the lecithin concentration so that less deviation was found at the "normal" concentration than at the other concentrations tested; similar findings were not observed in the present series with either D.-M. or D.-O. lecithin.

The results bear out the assumption that the sensitivity of the antigens (used in "normal" concentration) is connected with the number of double bonds in the fatty acids, the D. $-O$. lecithin being unsaturated, the D.-M. lecithin being saturated, and the natural lecithins lying somewhere between. It seems natural to ascribe the different, mainly quantitative, effects of the D.-M. and D.-O. lecithins to differences in solubility and reactivity. Faure (1949) showed that the use of hydrogenated natural lecithin in the same concentration as the unsaturated lecithin resulted in less sensitive antigens. Indeed, Kline $(1950,1954,1955)$ found it necessary to alter his antigen formula considerably when saturated synthetic lecithin was substituted for natural lecithin (E. or B.) and the results (though mainly qualitative) reported by Tonks, Allen, and Fowler (1955 a, b) also indicate that the lecithin concentration ought to be adjusted when different types of lecithins are employed. In a more recent preliminary report by Allen, Tonks, and Fowler (1956) it is concluded that "the nature of the fatty acids is not vital to the reactivity of the antigen". The present results show that it is possible to obtain 

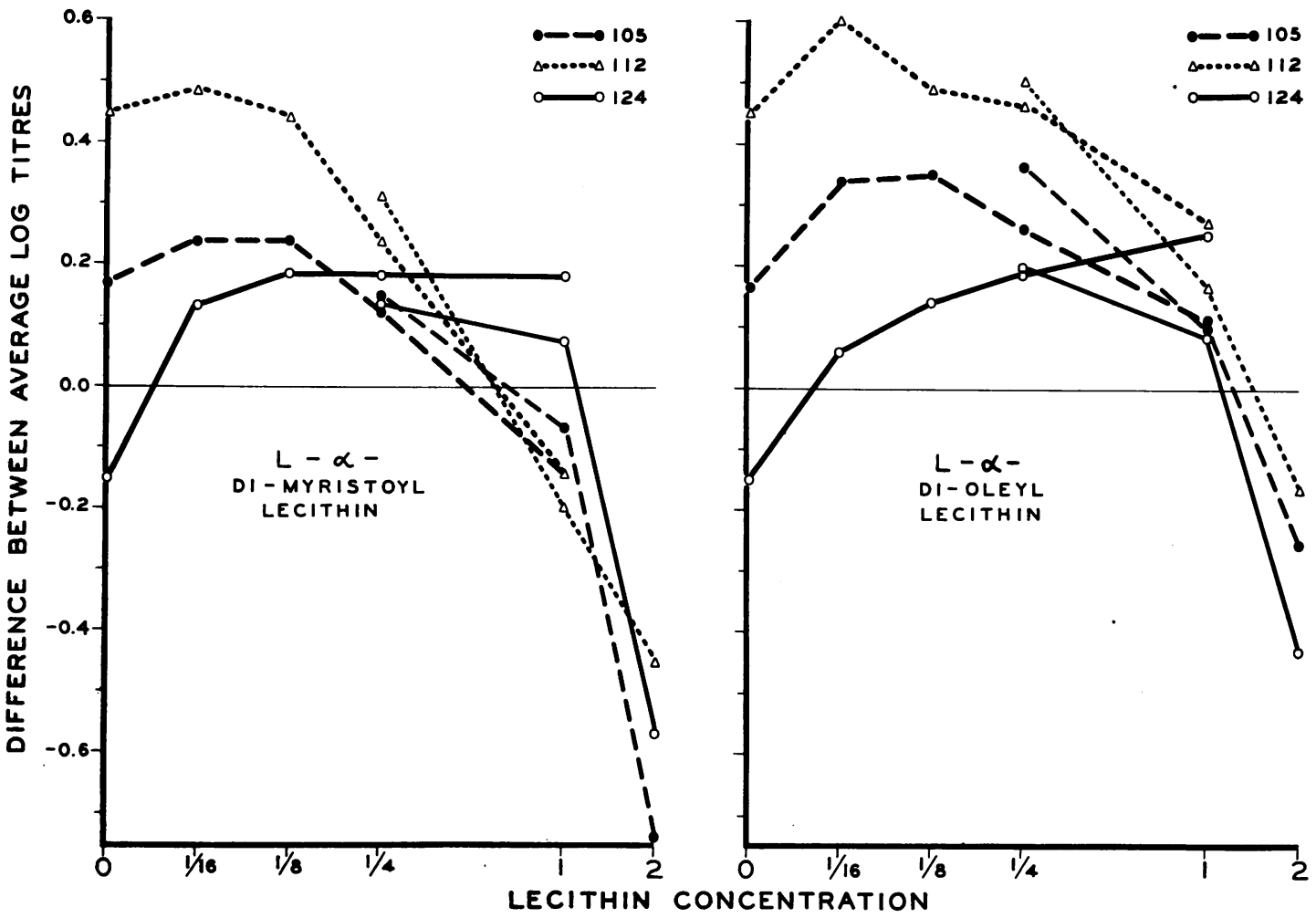

FIG. 2.-Comparison between a reference antigen prepared with "normal" (1) egg lecithin concentration and six test antigens with varied concentration of either L- $\alpha$-di-oleyl (D.-O.) lecithin or L- $\alpha$-di-myristoyl (D.-M.) lecithin.

Three chronic type syphilitic sera.

Abscissa: Lecithin concentration; 0 corresponds to the results obtained with the incomplete Card. Chol. antigen.

Ordinate: Difference between the reference antigen and the various test antigens in $\log _{10}$ values.

about the same titres with saturated and unsaturated lecithin when their concentrations are properly adjusted.

The specificity of antigens prepared with D.-M. and D.-O. lecithin in varying concentrations was not studied, but with the biologic false positive sera tested in this series a tendency to stronger reaction was observed with the D.-O. lecithin as compared with either the D.-M. lecithin or the E. lecithin at normal concentration.

Natural Lecithins.-Two experiments were performed:

(1) Three syphilitic sera $(108,114$, and 120$)$ and three biologic false positive sera $(130,131$, and 134) were tested on six experimental days:

Egg (E.) lecithin: September 23 and 27, and October 5.

Beef-heart (B.) lecithin: October 14 and 21 and

November 11, 1955.

The saline suspensions of the antigens were used immediately after preparation (zero time) and after
$15,30,60$, and 120 minutes' standing at room temperature.

(2) Owing to lack of serum, another set of freezedried sera was used, the three biologic false positive sera $(130,131$, and 134) being used in both sets in experiments. Altogether ten freeze-dried sera were tested on 2 or 3 days each; the sera were chosen with respect to both specificity and stage of disease:

Two acute syphilitic (105, 124, tested on January 1, February 2 and 16,1956 ),

Three chronic syphilitic $(110,123,125$, tested on February 2 and 16, 1956),

Three acute biologic false positive $(130,131,132$, tested on January 1, February 9 and 14, 1956),

Two chronic biologic false positive $(133,134$, tested on February 2 and 14, 1956) sera.

All the antigens were tested on each experimental day. The antigens with twice the "normal" concentration of natural lecithin (E. or B.) showed a 
considerably lower sensitivity than those with "normal" concentration. The antigens with $\frac{1}{2}$ the "normal" concentration showed a slightly higher sensitivity than those with the "normal" concentration, but the difference in sensitivity between antigens with "normal" and $\frac{1}{2}$ the "normal" lecithin concentration was only significant for the E. lecithin and then only with the first set of sera.

The actual figures as expressed in differences from antigen with "normal" concentration were:

(1) Twice the "normal": E. about -0.35 and B. about $-0.28 \log _{10}$ values.

(2) $\frac{1}{2}$ the "normal": E. about +0.07 and B. about $+0.03 \log _{10}$ values.

On the whole, the antigens prepared with $\mathrm{E}$. lecithin in half and double the "normal" lecithin concentration were found to deviate more in sensitivity from those prepared with "normal" concentration than the corresponding antigens prepared with B.. lecithin. In both experiments, significant differences were found between the antigen prepared with E. and B. lecithin in a "normal" concentration, but the relation as regards sensitivity differed in Experiments 1 and 2; antigen prepared with $\mathrm{E}$. lecithin gave weaker results than antigen prepared with B. lecithin in Experiment 1, and vice versa in Experiment 2.

Antigens prepared with E. and B. lecithin in a "normal" concentration are apt to be fairly interchangeable (Pontecorvo, Rappaport, Tompkins, and Vogelsang, 1955; W.H.O. Report Sero 64), so we must seek an explanation of the different relation between $E$. and B. lecithin in Experiments 1 and 2. This is rather difficult. The same antigen preparations were used in both experiments. It is possible that for some unknown reason the day-to-day variation was unusually great in the first experiments. In Experiment 2 all the antigens were tested on all the experimental days, thus eliminating the day-to-day variation. Another explanation might be that the "deviation from the rule" is due to special qualities of the sera chosen for the experiments.

For biologic false positive sera a far greater dayto-day variation was observed than for the syphilitic sera, and in many cases the haemolysis curves were atypical and flat, making the use of the Kärber method invalid. Fig. 3 shows three atypical haemolysis curves of the type with greater haemolysis in the first tube(s) than in the following tube; the three types of curves in Fig. 3 are marked 1, 2, and 3. In such cases, the 50 per cent. titres were estimated by the highest dilution with 50 per cent. haemolysis.

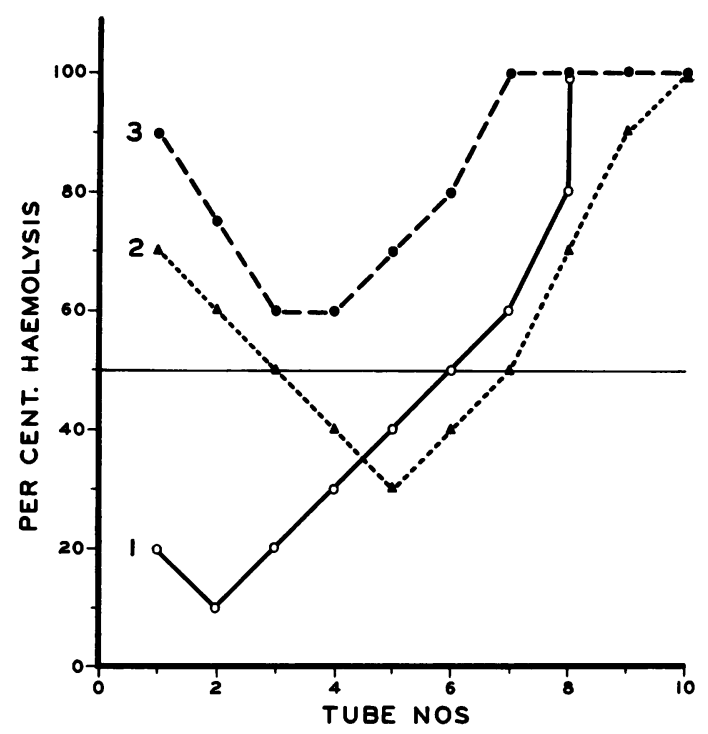

Fig. 3.-The three curves marked 1, 2, and 3 illustrate three atypical haemolysis curves.

The inter-serum variation also appeared to be greater than that found for the syphilitic sera. With due reservation, the main results were the same as those obtained for the syphilitic sera: antigens with half the "normal" lecithin concentration gave slightly less E. or the same B. average titres as those with "normal" concentration, and the antigens with twice the "normal" lecithin concentration gave lower average titres than those with "normal" concentration; the difference in this case, too, was greatest for the E. lecithin. For all three lecithin concentrations, the average titres with $B$. lecithin were significantly higher than those with $E$. lecithin (differences: $0 \cdot 13,0 \cdot 18$, and $>0.64 \log _{10}$ values).

The stronger reactions obtained with $B$. lecithin as compared with E. lecithin were also revealed in the maturation experiments. Here, curves were drawn for each of the three biologic false positive sera by plotting the maturation time (abscissa) against the haemolysis per cent. found in the first test tube (ordinate) for both types of lecithin (Fig. 4, opposite).

Fig. 4 shows that the haemolysis values were nearly always lower for the $B$. lecithin than for the E. lecithin, i.e. there was a tendency to stronger reaction with the first type of lecithin.

In addition, haemolysis curves were drawn for all three sera after various maturation periods; with increasing maturation time the number of tubes with slight or no haemolysis increased, and the lowest degree of haemolysis was obtained in the tubes containing higher dilutions, i.e. maturation 


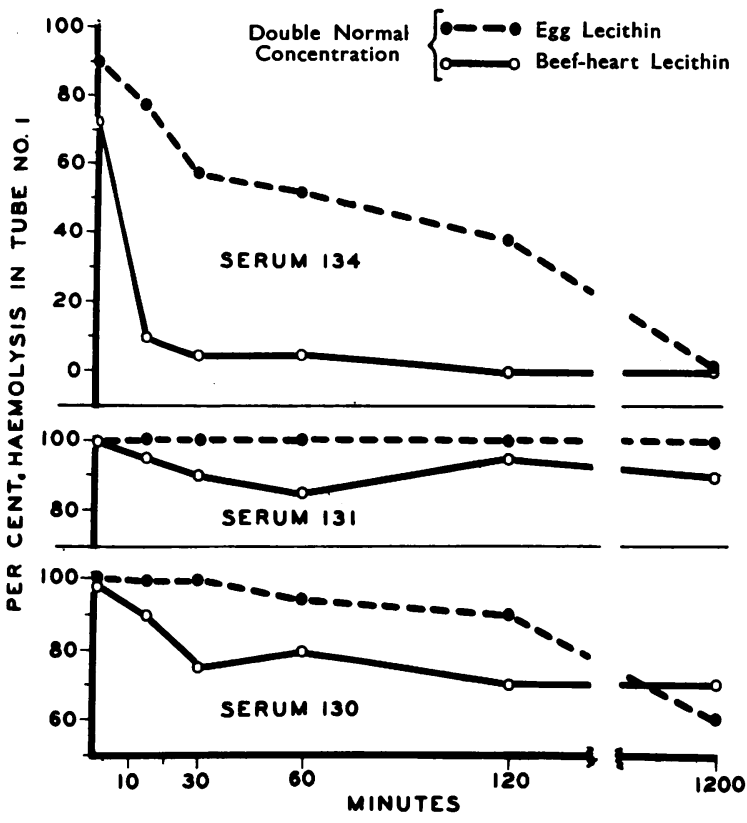

FIG. 4.-Ordinate: Average haemolysis per cent. (two experimental days) in the titration tubes with highest serum concentration for three biologically-false positive (B.F.P.) sera (130, 131, and 134) tested with cardiolipin antigens containing double the "normal" concentration of egg or beef-heart lecithin.

Abscissa: Maturation time for antigen suspensions.

occurred. Generally, the B. lecithin gave lower haemolysis values than the E. lecithin.

Storage Experiments.-In a previous series of experiments, using D.-M. lecithin in varying concentration and studying the effect of storage at $56^{\circ} \mathrm{C}$. for about 4 months, it was found that antigen containing D.-M. lecithin in a "normal" concentration suffered only a slight loss of sensitivity during storage, whereas antigen containing twice the "normal" lecithin concentration suffered a considerable loss $\left(0.2\right.$ to $\geq 0.9 \log _{10}$ values; 22 sera tested). In this series neither D.-M. nor D.-O. lecithin was tested for keeping qualities. A reference antigen prepared with E. lecithin was previously found to lose even less than the corresponding antigen prepared with D.-M. lecithin. On the average, $0.05 \log _{10}$ values; range about $0.3 \log _{10}$ values; thirteen sera tested.

In the present series, using 10 freeze-dried sera, the six antigens used in the experiments with the natural lecithins were compared with portions of the same antigens kept at $56^{\circ} \mathrm{C}$. for about 5 months. An exception was formed by the antigen prepared with $\frac{1}{2}$ the "normal" B. lecithin concentration, the heated portion of this antigen being lost during storage. The experiments were performed on January 13, 18, 20, and 23, 1956 (Table ).

The loss of sensitivity was different for $E$. and B. lecithin, and the average loss for $E$. lecithin used in a "normal" concentration was greater than in the former experiments (Average - $0.25 \log _{10}$ values; range 0.22 : five sera). After storage for about 5 months at $56^{\circ} \mathrm{C}$., antigen prepared with $\frac{1}{2}$ the "normal" E. lecithin concentration lost considerably in sensitivity. The loss was of the same order of magnitude for all the syphilitic sera (Average $-0.23 \log _{10}$ values; range 0.17 : five sera). The results with the biologic false positive sera were more variable, but here too a definite and even greater loss of sensitivity was observed. The antigen with twice the "normal" E. lecithin concentration showed no loss as compared with the two acute-type syphilitic sera, but a greater loss than that mentioned above with the three chronic-type syphilitic sera (Average, $-0.36 \log _{10}$ values: range 0.23 ). The results with the biologic false positive sera were highly variable (from an average gain of $\geq 0.38$ to an average loss of $0.04 \log _{10}$ values).

For the two antigens prepared with "normal" and twice the "normal" concentration of B. lecithin, either no loss or even a gain was observed with the syphilitic sera; with the biologic false positive sera the results were highly variable. Unfortunately, the antigens containing $\frac{1}{2}$ the "normal" B. lecithin concentration were lost during storage.

In earlier investigations (W.H.O. Report Sero 65; W.H.O. Report BS/278) of the effect of storage at $37^{\circ} \mathrm{C}$. for 3 months, some indication was found that B. lecithin did not keep as well as E. lecithin, both being stored separately and not as antigens. Pangborn (1957), however, reports on the better keeping qualities of complete antigens as compared with lecithin or cardiolipin stored alone.

In the present experiments, the two natural lecithins differed in their response towards the effect of heating, both lecithins possibly having a protective effect on the antigenic property, B. to a higher degree than $\mathrm{E}$.

When "complete" ethanolic antigens, consisting of cardiolipin (C), lecithin (L), cholesterol (Ch), and traces of unknown impurities are heated, this heating may act on one or more of the components.

It is not very likely that the cholesterol is affected by heating, but the unknown amount of impurities may probably be affected. The incidental impurities, whether protective or destructive, may vary from one lecithin batch to the other. 


\section{Conclusion}

For saturated (L- $\alpha$-di-myristoyl) and unsaturated $(\mathrm{L}-\alpha$-di-oleyl) synthetic lecithins used in different concentrations in cardiolipin antigens the serum titre response as measured in complement-fixation tests varied in the same way as previously found with saturated lecithin (Reyn and others, 1956). Generally, the antigens prepared with the unsaturated lecithin gave higher titres (at the same concentrations) than those prepared with the saturated lecithin. It was possible, however, by displacement of the individual serum curves to obtain the same titres by using 1.5 times less saturated than unsaturated lecithin. For sera from older cases of syphilis, this "relative potency" deviated but slightly from $1 \cdot 5$, whereas it varied from about 1 to 2 for sera from acute cases. Thus, in order to obtain the same average sensitivity, it would be nezessary to use different amounts of the two synthetic lecithins; in this way one might obtain the same average sensitivity if a great number of sera were tested, though there would always be the risk that some special sera would respond differently.

For the two natural lecithins (egg and beef-heart) which are usually regarded as interchangeable, at least at "normal" lecithin concentration, the response of the average serum titres to variation in lecithin concentration was similar to synthetic lecithins. Here, the beef-heart lecithin concentration curves were flatter than those for egg lecithin; in Experiment 1 the antigens prepared with beef-heart lecithin reacted more strongly than those prepared with egg lecithin, whereas the opposite was found in Experiment 2. This means that the lecithin serum titre response curves are different for the two natural lecithins.

An additional difference between the natural lecithins was observed in a storage experiment in which antigens prepared with different lecithin concentrations were exposed at $56^{\circ} \mathrm{C}$. for about 5 months.

The keeping qualities of the antigens were found to be different for the two natural lecithins, both possibly having a protective effect on the antigenic property, but in this case beef-heart lecithin to a higher degree than egg lecithin.

For the future evaluation of International Reference Preparations, it would seem appropriate to test them in other concentrations than those "normally" adopted. If, for instance, a new preparation of lecithin differed (although to a small degree) from the old one, this difference might not be so easily disclosed at "normal" lecithin concentration as at higher concentration, at which the lecithin $\sim$ serum response curve runs more steeply than at the "normal" lecithin concentration. This holds true for the most commonly employed antigen formula in the $\mathrm{CF}$ technique: Cardiolipin: 1, Lecithin: 5, Cholesterol: 17.

Hence, it is suggested that to compare new reference batches with the old batches, antigens containing the concentration of cardiolipin, lecithin, and cholesterol commonly used in the various techniques (Chron. Wld Hlth Org., 1955) and also in the "neighbourhood" of these concentrations should be compared. This might give a better guarantee against the risk of gradual systematic changes in the potency of the reference preparations; it would also reveal something of the effect of errors in the production of antigens with these preparations.

It might also be worthwhile to subject these preparations (single and combined in antigens) to heating; defects in the keeping qualities of the new preparations might thereby be disclosed.

Our thanks are due to Professor Baer for kindly putting samples of the synthetic lecithins at our disposal.

\section{REFERENCES}

Allen, R. H., and Mason, M. A. (1952). Canad. J. Publ. Hlth, 43, 128. Tonks, D. B., and Fowler, E. (1956). "First International Symposium on Venereal Diseases and the Treponematoses". Washington, D.C.

Baer, E. (1953). J. Amer. chem. Soc., 75, 621

Buchnea, D., and Newcombe, A. G. (1956). Ibid., 78, 232.

Chron. Wld Hlth Org. (1955). 9, 170.

Chron. Wld Hith Org. (1955). 9, 170. 76, 465.

Finney, D. J. (1947). "Probit Analysis", p. 39, University Press, Cambridge.

Harris, A., and Portnoy, J. (1944). J. vener. Dis. Inform., 25, 353.

Kent, J. F., Boyd, H. M., and Sanders, R. W. (1948). Bull. U.S. Army med. Dept., 8, 284.

Kline, B. S. (1950). Amer. J. Syph., 34, 460.

(1954). Amer. J. clin. Path., 24, 859.

(1955). Ibid., 25, 971 .

Kolmer, J. A., and Lynch, E. R. (1948). J. vener. Dis. Inform., 29, 166. Lundbäck, H. (1952). "Studies on the Wassermann Reaction";. Thesis, Uppsala.

Maltaner, E., and Maltaner, F. (1945). J. Immunol., 51, 195.

Mørch (1955). Cited by Schmidt (1951).

Nelson, R. A., and Mayer, M. (1949). J. exp. Med., 89, 369.

Pangborn. M. C. (1957). Personal communication.

Pangborn, M. C. (1957). Personal communication. Maltaner, F., Tompkins, ". N., Beecher, T., Thompson, W. R.,
and Flynn M. R. (1951). "Cardiolipin Antigens". World Health Organization, Monograph Series, No. 6. Geneva.

Price, I. N. Orpwood (1953). Brit. J. vener. Dis., 29, 12.

1953b). Ibid., 29, 78.

(1953c). Ibid., 29, 175.

(1954). Ibid., 30, 210.

Pontecorvo, M., Rappaport, F., Tompkins, V., and Vogelsang, T. (1955). Bull. Wld Hlth Org., 13, 323.

"Report on the Comparison of International Reference Preparations of Cardiolipin and Lecithin". WHO/VDT/SERO 64.

"Report on the Thermostability of International Reference Preparations of Cardiolipin and Lecithin". Unpublished Working Document. WHO/VDT/SERO 65.

"Note on the International Reference Preparations of Cardiolipin and Lecithin". Unpublished working Document WHO/BS/278 Add. 1 .

Reyn, A., Bentzon, M. W., and Hartmann, J. (1956). Brit. J. vener. Dis., 32, 40 .

Schmidt, H. (1951). Ibid., 27, 23.

(1955a). Acta path. microbiol. scand., 36, 141

1955b). Ibid., 36, 147.

(1957). Personal communication.

Tonks, D. B., Allen, R. H., and Fowler, E. (1955a). "Symposium on Recent Advances in the Study of Venereal Diseases". Abstracts of Papers, No. 12. Washington, D.C. of Papers, No. 12. Washington, D.C. 1 (1955). Brit. J. vener. Dis., 31, 180. 